\title{
UNA NUEVA Y FRAGMENTARIA VERSIÓN DEL ROMANCE «MUERTO YAZE DURANDARTE» EN UNA PROBATIO CALAMI*
}

\author{
Cleofé TATO \\ Universidade da Coruña
}

En los códices e impresos antiguos solemos encontrar muestras de lo que se ha dado en llamar probatio calami sive pennae: sobre los márgenes, espacios en blanco y folios de guarda, a menudo una mano (o más) calibra, prueba la pluma; a veces la deja correr con despreocupación y llega a perfilar algún dibujo, otras tan solo rasguea un garabato y, ocasionalmente, engarza unas cuantas palabras. En apariencia, estos ensayos de escritura no hacen sino deteriorar el documento, pero algunos de ellos se han revelado muy rentables para el estudioso de la literatura y aun para el linguiista; cabe recordar, por ejemplo, que tal vez uno de los más antiguos testimonios del italiano nos lleve a una de esas probationes pennae, una adivinanza trazada por una mano del siglo VIII o IX ${ }^{1}$.

En muchos casos, se trata de apuntes llevados a cabo bastante después de la copia de la obra que acompañan, sin relación con su contenido y de escaso interés para su estudio; sin embargo, su examen no debe desdeñarse. Y es que, si cualquier ámbito de la Historia de la Literatura está sujeto a la incidencia de la casualidad afortunada, los textos que se difundían oralmente parecen beneficiarse de forma especial de estos ocasionales ejercicios de la pluma, sobre todo los que pervivían en la memoria porque llegaban por vía tradicional, como roman-

\footnotetext{
* Este artículo se integra en el marco del Proyecto de Investigación HUM 2007-63484/FILO, financiado por el Ministerio de Educación y Ciencia. Quiero agradecer especialmente a Mariano de la Campa sus sugerencias y observaciones a la primera versión de este trabajo.

${ }^{1}$ Se halla en un folio de un oracional mozárabe de la Biblioteca Capitolare de Verona; no obstante, la modalidad lingǘstica no es suficientemente clara, de modo que puede tratarse de una muestra de latín. Véase Carlo Tagliavini, Orígenes de las lenguas neolatinas: Introducción a la filología romance, México, FCE, 1975, págs. 696-699 (original en italiano publicado en 1949); allí se ofrece una reproducción facsímil de la adivinanza.
} 
ces y villancicos, pero también los que la moda de un momento popularizaba o simplemente los que el receptor aprendía por gusto o interés. Sin que falten muestras de pruebas de escritura en otros ámbitos (como ocurre, por ejemplo, en la poesía cancioneril ${ }^{2}$ ), la realidad apunta a que este fenómeno alcanza mayor relevancia en la literatura tradicional, que no de modo infrecuente documentamos así. $\mathrm{Y}$ alguna de esas probationes calami posee muy poca entidad gráfica, como es el caso de la recogida por Samuel Armistead en unos papeles aprovechados para encuadernar unos códices árabes: allí figura, entre otros, un ensayo de escritura en el que el amanuense consigna «conde claros con amo», segmento que remonta al segundo dieciseisílabo del conocido romance del Conde Claros insomne («Media noche era por filo, los gallos querían cantar / Conde Claros con amores no podía reposar»); ello permite a este investigador encontrar argumentos para sustentar la idea de la existencia de un romancero morisco ${ }^{3}$.

Otros estudiosos posteriores han dado cuenta de más romances y villancicos registrados de la misma manera ${ }^{4}$. El hecho de que de modo tan significativo estas formas poéticas se relacionen con tales fenómenos de la escritura, sin duda,

\footnotetext{
${ }^{2}$ Sobre el interés de las pruebas de pluma en este ámbito llamó ya la atención Ángel Gómez Moreno hace casi 25 años; véase «Dos decires de recuesta y algunas notas sobre poemas sueltos en el siglo XV», Revista de Filología Española, LXV, 1985, págs. 109-114 (especialmente pág. 110, nota 6). Algunas muestras de versos cancioneriles así recogidos pueden verse en Brian Dutton, «Dos referencias curiosas a un poema de Juan Alfonso de Baena», Actas del VIII Congreso de la Asociación Internacional de Hispanistas (22-27 agosto 1983, Brown University, Providence, Rhode Island), I, A. David Kossoff et al., eds., Madrid, Istmo, 1986, págs. 491-496; Jane Whetnall, «Adiciones y enmiendas al Cancionero del siglo XV», Cancionero Studies in Honour of Ian Macpherson, Alan Deyermond, ed., London, Department of Hispanic Studies-Queen Mary and Westfield College, 1998, págs. 195-218 (especialmente pág. 210); Víctor Infantes y Juan Carlos Conde, «La letra sobre la letra. Un testimonio manuscrito inédito de Juan del Encina en unas Constituciones (1498)», La literatura popular impresa en España y en la América colonial. Formas \& temas, géneros, funciones, difusión, historia y teoría, Pedro M. Cátedra, dir., y Eva Belén Carro Carbajal et al., eds., Salamanca, SEMYR-Instituto de Historia del Libro y de la Cultura, 2006, págs. 671-721.

${ }^{3}$ Véase Samuel G. Armistead, «¿Existió un romancero de tradición oral entre los moriscos?», Actas del Coloquio Internacional sobre Literatura aljamiada y morisca, Álvaro Galmés de Fuentes, ed., Madrid, Gredos, 1978, págs. 211-236, especialmente pág. 226.

${ }^{4}$ Algunas de las referencias bibliográficas que recoge Whetnall en su mencionado artículo, que ahora obvio, se refieren, precisamente, a hallazgos de textos tradicionales que tienen correspondencia con el centro de interés de su trabajo, la poesía cancioneril (véase «Adiciones y enmiendas», pág. 196, nota 2). Pero pueden añadirse a esa relación otros trabajos que recuperan textos tradicionales: Mari Carmen García, «Romances, villancicos y refranes en unos garabatos del siglo XV al XVI», La Corónica, 22:2, 1993-1994, págs. 124-132, y Juan Carlos Conde, «Otro testimonio manuscrito de un villancico tradicional», Journal of Hispanic Research, 1, 1992-1993, págs. 203-206. También Mariano de la Campa y Belinda García Barba recuperan el contenido del f. 356 del ms. 7896 de la Biblioteca Nacional, que «parece un ensayo de escritura donde alguien escribió» cinco pareados dieciseisílabos correspondientes a tres temas distintos del romancero; véase «Versiones medievales inéditas de varios romances en un romancerillo manuscrito fragmentario», Medievalia, 25, 1997, págs. 26-42, especialmente pág. 41.
} 
ha de vincularse con el carácter oral de su transmisión y aun con la posibilidad de que algunos de estos fragmentos trazados a vuelapluma y sin excesivo cuidado estuviesen musicados: quien los copia escribe lo primero que se le ocurre; los romances, integrados en su vida cotidiana, aflorarían a su mente con facilidad, de la misma manera que hoy cualquiera puede recordar la letra de algunas canciones muy popularizadas. En este sentido, cabe señalar que, según Armistead hace notar, algunos de los primeros testimonios baladísticos escandinavos se registran, precisamente, en pruebas de pluma casuales ${ }^{5}$.

En las páginas que siguen dedicaré mi atención a uno de esos ensayos gráficos registrado en un códice de principios del XVI que hoy se custodia en la Biblioteca Nacional de Madrid (ms. 3338); el manuscrito, en bastante buen estado de conservación, nos ha transmitido varias obras de carácter científico, entre las que se encuentra la Flor de Cirugía de Fernando de Córdoba, el texto más relevante de cuantos allí se incluyen ${ }^{6}$. No es la probatio pennae que aquí analizo la única que se localiza en el códice, pero sí, posiblemente, la que ofrece mayor interés ${ }^{7}$.

Da la sensación de que, cuando el vuelto del último folio estaba totalmente en blanco, una mano posterior a las que intervienen en la copia del códice (no muy alejada del momento en que se confecciona este), con una letra menos cuidada y más cursiva, hace una prueba de pluma y copia en el centro del folio los dos primeros dieciseisílabos de un romance viejo cuyo íncipit reza «Muerto estava Durandarte» ${ }^{8}$; algo después, otras manos distintas aprovechan el espacio en blanco que queda en la parte superior e inferior del folio e introducen otras anotaciones.

La datación de este muy fragmentario testimonio en el siglo XVI, refuerza la idea —que, por otra parte, ya teníamos— de que la pieza era muy conocida en la primera mitad de la centuria; y es que, según veremos, varios de los testimonios impresos nos llevan hacia 1550 , lo cual implica que circularía con anterioridad ${ }^{9}$. Lo cierto es que el tema del corazón de Durandarte parece arrancar

\footnotetext{
${ }^{5}$ Véase «¿Existió un romancero de tradición oral?», pág. 277, nota 46.

${ }^{6}$ Ésta última producción ha sido estudiada y editada por José Ignacio Pérez Pascual; véase $L a$ «Suma de la flor de cirugía» de Fernando de Córdoba, Noia, Toxosoutos, 2002, en donde puede encontrarse un breve análisis sobre la materialidad del manuscrito (págs. 48-51).

${ }^{7}$ En el folio final figuran otras que tampoco guardan relación con el contenido del volumen; de ellas me ocupo en «Unos versos de una carta de amores del siglo XVI en unas probationes calami», Acta Poética, en prensa.

${ }^{8}$ Deja un pequeño margen a la izquierda $\mathrm{y}$, como no tiene espacio para la última palabra (montaña), la superpone sobre la primera línea de escritura.

${ }^{9}$ Por más que disociemos los testimonios impresos del romancero antiguo y la tradición oral (véase Mario Garvin, «Scripta manent»: Hacia una edición crítica del romancero impreso (siglo XVI), Madrid-Frankfurt, Iberoamericana/Vervuert, 2007, págs. 17-28), cabe presumir, en vista del éxito editorial y de la pervivencia en la tradición oral moderna de «Muerto yaze Du-
} 
de la composición «Oh Belerma, oh Belerma», la cual alcanzó una enorme difusión (es uno de los romances más glosados en la centuria ${ }^{10}$ ): incorporada en pliegos sueltos y en colecciones de romances, destaca especialmente porque da origen a muchas citas en ensaladas ${ }^{11}$. Este romance se inscribe en el ciclo carolingio:

recrea la derrota de Roncesvalles, centrándose en la muerte de un caballero llamado Durandarte (nombre que en la épica francesa es el de la espada de Roldán), primo de Montesinos [...], a quien se supone tambien caballero de la corte de Carlomagno. Antes de morir, Durandarte encarga a su primo que le arranque el corazón y se lo lleve como muestra de amor a Belerma, la dama a la que servía ${ }^{12}$.

randarte», que nuestro romance hubiese circulado oralmente bastante antes de que apareciesen las primeras manifestaciones escritas.

${ }^{10}$ Piacentini y Periñán señalan que, tras las 19 glosas de La bella malmaridada, sigue el de Belerma con siete (véase Giuliana Piacentini y Blanca Periñán, Glosas de romances viejos. Siglo XVI, Pisa, ETS, 2002, pág. 14). Al decir de la primera de estas dos estudiosas, el romance «no es uno de los más antiguos entre los carolingios, pero fue sin duda uno de los más difundidos y más atestiguados, directa o indirectamente, en sus versiones enteras o en versos sueltos que llegaron incluso a proverbializarse. Fue también uno de los más glosados, parafraseados y, naturalmente, parodiados»; véase Giuliana Piacentini, «Una lectura de las glosas del Romance de Belerma», en Actas del Congreso Romancero-Cancionero (UCLA 1984), I, Enrique Rodríguez Cepeda, ed., con colaboración especial y «Bibliografía Crítica» de Samuel G. Armistead, Madrid, José Porrúa Turanzas, 1990, págs. 153-164 (especialmente pág. 153). Se ofrece la referencia de ocho glosas y una contrahechura de «Oh Belerma, oh Belerma» en Diego Catalán, «Hallazgo de una poesía marginada: el tema del corazón de Durandarte», Arte poética del romancero oral: Parte $2^{a}$ : Memoria, invención, artificio, Madrid, Fundación Ramón Menéndez Pidal-Siglo Veintiuno, 1998, págs. 1-34, especialmente pág. 3, nota 2, parcialmente accesible en la bitácora que hasta hace poco dirigió el propio Diego Catalán Romancero de la Cuesta del Zarzal (<http://cuestadelzarzal. blogia.com> [consultada: 12-06-08]). Véase, asismismo, Piacentini y Periñán, Glosas de romances viejos, págs. 200-219, núm. 41. A propósito de otra contrahechura de «Oh Belerma, oh Belerma», esta vez a lo divino, véase infra pág. 297.

11 Y esto, en opinión de Díaz-Mas, explica el porqué de la parodia cervantina posterior: «se trataba de un romance muy conocido, que estaba en boca de todos, y de ahí que cualquier lector estuviese capacitado para entender la broma que sirve de sustento a ese capítulo del Quijote (II.23)» (Paloma Díaz-Mas, «Algo más sobre romances [y canciones] en ensaladas», Nueva Revista de Filología Hispánica, XLI, 1993, págs. 231-250; la cita en la pág. 231). «Oh Belerma, oh Belerma» está muy presente en pliegos sueltos, pero se recoge en pocas antologías; Di Stefano apunta solo tres, de entre 1547 y 1551: el Cancionero de romances sin año, el de 1550 y la Tercera parte de la Silva de varios romances, aparecida en Zaragoza en 1551 (véase Giuseppe Di Stefano, «La difusión impresa del romancero antiguo en el siglo XVI», Revista de Dialectología y Tradiciones Populares, XXXIII, 1977, págs. 373-411). En opinión de Catalán, la versión de «Oh Belerma, oh Belerma» del Cancionero de romances sin año fue tomada por Nucio de un pliego suelto que contiene una glosa de Alberto Gómez («Hallazgo de una poesía marginada», pág. 3, nota 2), pliego que Garvin sitúa entre 1533 y 1536 pero que, a su juicio, no es la fuente de la que bebió Nucio («Scripta manent», págs. 215-216).

12 Paloma Díaz-Mas, ed., Romancero, estudio preliminar de Samuel G. Armistead, Barcelona, Crítica, 1994, pág. 212. Como esta editora hace notar, constituye «una buena muestra de la 
No obstante, ese marco histórico-legendario no es sino un trasfondo desdibujado, algo particularmente perceptible en varias de las glosas que conoce: presumiblemente lo que llamaba más la atención del público era el peso del amor y de la muerte, temas bienqueridos de la poesía de cancionero que determinaron el éxito de «Oh Belerma, oh Belerma» ${ }^{13}$. La composición nos presenta la agonía del protagonista (moribundo tras la batalla) y su último e intenso parlamento en el que se dirige a su primo Montesinos para expresarle la última voluntad, que no guarda relación con la obligación del guerrero (cumplida al parecer sobradamente), sino con el deber como amante, nunca olvidado en vida y tampoco a la hora de la muerte: dispone que su corazón le sea entregado a su amada Belerma ${ }^{14}$.

Esta composición dará lugar, muy pronto, a una continuación, nuestro texto ${ }^{15}$; en esta secuela,

reelaboración de temas carolingios en la tradición hispánica, incluyendo la invención de nuevos episodios y personajes ausentes en la épica y la novela caballeresca francesas» (ibíd.).

${ }^{13}$ Véase Piacentini, «Una lectura de las glosas del Romance de Belerma», pág. 153. Desde este punto de vista, también interesa señalar que en el Cancionero de romances figura entre los textos que tratan de amores y, como precisa Garvin, «su inclusión entre éstos de amores no es un error de Nucio sino una clara confesión del modo en que se entendían ciertos romances» ( «Scripta manent», pág. 216).

${ }^{14}$ No se ofrece el nombre de la batalla ni el del protagonista: el público no precisaría esos detalles. Como con acierto apunta Piacentini, el «amante es héroe guerrero y héroe de la pasión amorosa, y en su herida y muerte se mezclan y exaltan el valor militar sacrificado y la fidelidad de amor frustrada: agonía física y desgarramiento sentimental coinciden y se refuerzan recíprocamente y con un equilibrio ejemplar; lejana en el trasfondo, Belerma es la protagonista ausente de la típica relación cortés, ausente y tardíamente benévola» («Una lectura de las glosas del Romance de Belerma», págs. 153-154). Ha de notarse que la «lanzada» que, según alguna de las versiones de «Oh Belerma, oh Belerma», aqueja a Durandarte (posible causa de su muerte) bien puede asociarse a la prototípica lanzada, bélica y amorosa al tiempo, del mártir de amor por excelencia, Macías; en uno de sus más conocidos textos, que dirige a su señora, «Ay señora en que fiança» (ID 0047, según las convenciones de Dutton; véase infra nota 19), la lanzada es amorosa (vv. 3244). Cuando, siglos después, Gonzalo Argote de Molina nos habla de Macías recuerda algunos de sus versos y se refiere a la lanza, que fue también el instrumento físico de la herida mortal de Macías, quien, en efecto, según las distintas versiones de su vida (en esto coincidentes), fue atravesado por una lanza arrojada por el marido de la dama a quien él profesaba su amor. Sobre Macías véase Andrea Zinato, ed., Macías: l'experienza poetica galego-castigliana, Venezia, Cafoscarina, 1996 (para el poema, págs. 69-71; para las versiones de su vida, págs. 119-127).

${ }^{15}$ Catalán considera el romance de «Oh Belerma, oh Belerma» «indudablemente del siglo $\mathrm{XV} »$ («Hallazgo de una poesía marginal», pág. 14), idea en la que había incidido Piacentini, que situaba la posible época de formación del romance a fines del siglo XV («Una lectura de las glosas del Romance de Belerma», pág. 153). La vinculación que con él tiene «Muerto yaze Durandarte» es innegable, y resulta razonable suponer que «Oh Belerma, oh Belerma» haya sido su matriz; en este sentido, Rodríguez-Moñino ya calificaba al que aquí estudiamos de «lógica conclusión» del de Belerma; véase Damián López de Tortajada, Floresta de varios romances (Valencia 1652), Antonio Rodríguez-Moñino, ed., Madrid, Castalia, 1970, pág. 16. Es posible que el romance de Durandarte se gestase ya sobrepasado el Medievo, a principios del siglo XVI, como sugiere Catalán; con todo, los dos textos (el de Belerma y el de Durandarte) son considerados 
Montesinos, después de muerto el caballero enamorado (a quien se identifica en el nuevo romance como Durandarte, cosa que «O Belerma, o Belerma» no hacía), cumple el encargo de sacarle el corazón. Este segundo acto de la historia alcanzó también extraordinaria popularidad desde los primeros decenios del siglo XVI, según muestra el hecho de que nos sean conocidas seis versiones diversas del romance (la mayor parte de ellas también glosadas) de la primera mitad del siglo ${ }^{16}$.

Así, pues, en nuestra pieza el amante de Belerma, identificado por su nombre en el cierre del primer octosílabo, yace muerto mientras asistimos a los afanes de Montesinos para llevar a cabo su difícil encomienda; Montesinos profiere también las pocas palabras que se oyen, dirigidas, en patético llanto, al muerto inerme ${ }^{17}$.

«Muerto yaze Durandarte» habría circulado como pieza independiente durante la primera mitad del XVI (y así figura en algún pliego suelto de hacia 1550), pero la conexión entre los «dos actos de la historia» puede explicar que, cuando en 1550 Martín Nucio saca a la luz una nueva versión del Cancionero de romances, el texto de Durandarte se copie sin solución de continuidad tras el de Belerma, cosa que, por otra parte, propiciaba tanto la asonancia (á.a: la misma para los dos romances) como el contenido (el de Durandarte, temáticamente, resulta ser, como se ha dicho, una prolongación de aquél ${ }^{18}$ ).

romances viejos y figuran en gran parte de las antologías de este tipo (véase, no obstante, sobre el problema que entraña esta clasificación, el trabajo de Garvin «Scripta manent», págs. 47-51).

16 «Hallazgo de una poesía marginada», pág. 3. Catalán intenta, en realidad, filiar los testimonios que maneja (que no son todos los aquí contemplados) y establece seis versiones (a las que podría añadirse alguna más; véase infra págs. 288-290); puede accederse al texto de varias de esas versiones a través de la Sede del Proyecto sobre el Romancero pan-hispánico, dirigido por Suzanne Petersen, pinchando en la Base de datos de romances y procediendo a buscar por el título (información accesible en la dirección <http://depts.washington.edu/hisprom/> [consultada: 12-06-08]).

${ }^{17}$ Es interesante constatar cómo la atención de la rúbrica que presenta el romance en alguna de las colecciones que lo recogen apunta al protagonista vivo, el agente encargado de cumplir la última voluntad de Durandarte: Romance de Montesinos; véase Silva de romances (Zaragoza, 1550-1551). Ahora por vez primera reimpresa desde el siglo XVI en presencia de todas las ediciones, Antonio Rodríguez-Moñino, ed., Zaragoza, Ayuntamiento de Zaragoza, 1970, pág. 490.

${ }^{18} \mathrm{Y}$ es que, entre los romances que Nucio «mejora» con respecto a los ofrecidos en el Cancionero de romances sin año se encuentra «Oh Belerma, oh Belerma», que «Conserva el texto tal como se estampó primitivamente, pero añade la continuación que comienza Muerto yace Durandarte, con veinte versos»; véase Cancionero de romances: (Anvers, 1550), Antonio RodríguezMoñino, ed., Madrid, Castalia, 1967, pág. 26, y Antonio Rodríguez-Moñino, La Silva de romances de Barcelona, 1561: Contribución al estudio bibliográfico del Romancero español en el siglo XVI, Salamanca, Universidad de Salamanca, 1969, págs. 77-97. Sin embargo, ha de advertirse que, en el Cancionero de romances sin año, la pieza «Oh Belerma, oh Belerma» se cierra con la voz Fin, frente a lo que sucede en algún texto de los que luego fueron «mejorados» en 1550 (en «Miraua de Campo Viejo» o en «La triste reyna de Napoles» alguna indicación nos previene de que están incompletos en la primera recopilación de Nucio); véase Cancionero de romances en que están recopilados la mayor parte de los romances castellanos que fasta agora sean compues- 
No ha de olvidarse tampoco que, pese a la importancia de «Oh Belerma, oh Belerma» y pese a la fuerte imbricación que con él tiene «Muerto yaze Durandarte», alguno de los episodios de la historia de desamor entre ambos personajes había sido objeto de atención en la poesía cancioneril bastante antes: en la sección de romances del Cancionero general que da a conocer Hernando del Castillo en 1511, se incluye ya el romance «Durandarte, Durandarte», que es glosado por el poeta Soria inmediatamente después ${ }^{19}$. Por otra parte, y como bien señala Catalán, en la poesía trovadoresca y en la prosa caballeresca y sentimental, es un tópico recurrente presentarnos a un enamorado que, por el hecho de amar, enajena su corazón, que pasa, así, a ser pertenencia de su ama$\mathrm{da}^{20}$. No es imposible, pues, que el público de la poesía cancioneril, tan familiarizado con estos asuntos, hubiese propiciado el desarrollo de la historia de desamor entre Belerma y Durandarte con el «segundo acto» en que interviene Montesinos; y es que, como veíamos para el romance «Oh Belerma, oh Belerma», el amor y la muerte, temas favoritos entre los poetas cuatrocentistas, habrían sido las claves del éxito de «Muerto yaze Durandarte» ${ }^{21}$. De hecho, en el más antiguo testamento de amor de la literatura cancioneril, el Arcediano de Toro, poeta del reinado de Juan I (según nos aclara Santillana en su Prohemio $e$ Carta, SPC), entre las mandas que ordena, establece, precisamente, la misma

to, Martín Nucio, Amberes, sin año [ed. fac. con introducción de Ramón Menéndez Pidal, Madrid, CSIC, 1945]). Con todo, no siempre en el Cancionero de romances sin año se marcan las composiciones que aparecerán mejoradas en $1550 \mathrm{y}$, por otra parte, no puede descartarse por completo que, además de la mala calidad de los ejemplares empleados o de la mala memoria de los informantes (motivos apuntados por el propio Nucio en el Cancionero de romances sin año para excusar los problemas de los textos), haya otras razones que expliquen el añadido de «Oh Belerma, oh Belerma» en 1550 (véanse, así, otros supuestos para otros romances en Garvin, «Scripta manent», págs. 220-232).

${ }_{19}$ Véase Hernando del Castillo, Cancionero general, II, Joaquín González Cuenca, ed., Madrid, Castalia, 2004, págs. 546-547. Este mismo romance también se recoge en otras fuentes cancioneriles de las inventariadas por Dutton: MP4g-514 (290v.); MP7-59 (244v.); 14CG-495 (115v); $17 *$ RM-5 (4v) y 20*DS-1 (1r); en MP4 aparece como músico Millán y, además, ha sido glosado también en LB1-196 (63r-v), en donde no es clara la autoría, pues la rúbrica solo precisa glosa del romance durandarte; véase Brian Dutton, El cancionero del siglo XV (ca. 1360-1520), Salamanca, Biblioteca Española del Siglo XV-Universidad de Salamanca, 1990-1991, 7 vols., obra que, en adelante, citaré abreviadamente $\operatorname{Cs} X V$ (me refiero a las fuentes cancioneriles del siglo XV, así como a los textos poéticos, valiéndome de las convenciones aquí empleadas). A estas fuentes de «Durandarte, Durandarte», hay que añadir algunas otras posteriores que sobrepasan el marco temporal del CsXV; véase José J. Labrador Herraiz y Ralph A. DiFranco, «Del XV al XVII: doscientos poemas», «Nunca fue pena mayor»: Estudios de literatura española en homenaje a Brian Dutton, Ana Menéndez Collera y Victoriano Roncero López, eds., Cuenca, Universidad de Castilla-La Mancha, 1996, págs. 367-418, especialmente pág. 381. Véase también Piacentini y Periñán, Glosas de romances viejos. Siglo XVI, págs. 77-83, n. ${ }^{\circ} 12$.

20 «Hallazgo de una poesía marginada», pág. 2.

${ }^{21}$ A juicio de Piacentini, esas fueron, desde luego, las del éxito del Romance de Belerma (véase supra nota 13); nada impide hacerlas extensivas a la pieza que ahora nos ocupa. 
que Durandarte encarga a Montesinos: que su corazón, tras su muerte, le sea entregado a su señora, dueña de él ya en vida y, como Belerma, poco propicia a otorgar favores a su enamorado ${ }^{22}$. Así reza la estrofa quinta del Arcediano:
O meu coraçón muy leal otrossí mando, amigos, jsí veja prazer! aa muy linda e de grant poder, miña señora que por meu mal vi; pois que ena vida, amigos, foi seu, seja ena morte, assí mando eu, pois qu'esta morte d'ela resçebí ${ }^{23}$.

La misma situación se refleja, como bien advirtieron John Gornall y Colin Smith, cuando Amadís, en ese momento bajo el nombre de Caballero de la Verde Espada, antes de emprender una de sus aventuras se dirige a Galandín, su escudero, y le dice: «y ruégote mucho que si aquí muriere, procures de llevar a mi señora Oriana aquello que es suyo enteramente, que será mi corazón. Y dile que gelo embío por no dar cuenta a Dios de cómo lo ajeno levaba conmigo» ${ }^{24}$.

Lo cierto es que, aun cuando el éxito editorial de buena parte del romancero viejo cae progresivamente en declive a lo largo del siglo XVI, «Oh Belerma, oh Belerma» $\mathrm{y}$ «Muerto yaze Durandarte» cuentan con un importante número de presencias en fuentes impresas. El primero, como ya vimos, conoce una gran difusión; «Muerto yaze Durandarte», además de figurar en pliegos y en colecciones de romances quinientistas, todavía se incluye en un pliego del XVII y en una de las antologías de esa centuria (y también se conserva en varias fuentes manuscritas del XVI). En el Siglo de Oro, Góngora y Cervantes se harán eco de la relación Durandarte-Belerma y de la manda testamentaria de

\footnotetext{
22 Véase $E l$ «Prohemio e carta» del Marqués de Santillana y la teoría literaria del s. XV, ed. crítica, estudio y notas de Ángel Gómez Moreno, Barcelona, PPU, 1990, pág. 62. Un breve perfil de la biografía del Arcediano de Toro puede encontrarse en Ricardo Polín, A poesía lírica galego-castelá (1350-1450), Santiago de Compostela, Universidade de Santiago de Compostela, 1994, págs. 49-51.

${ }^{23}$ Se trata del poema «Pois que me vejo a morte chegado» (ID 1442), solo recogido en PN1. Cito por Cancionero de Juan Alfonso de Baena, Brian Dutton y Joaquín González Cuenca, eds., Madrid, Visor, 1993, pág. 556.

${ }^{24}$ Cito el texto por Garci Rodríguez de Montalvo, Amadís de Gaula, Juan Manuel Cacho Blecua, ed., II, Madrid, Cátedra, 1988, pág. 1141; véase también John Gornall y Colin Smith, «Góngora, Cervantes, and the Romancero: some Interactions», Modern Language Review, 80, 1985, págs. 351-361, especialmente pág. 351. Quizás, en el Amadís, según suponen Gornall y Smith, quien tal escribía conocía el romance de Durandarte (ibíd.), por más que, como recuerda Cacho Blecua, el mismo motivo se localiza en la tradición artúrica: en la Demanda del Sancto Grial (332b), la reina Ginebra antes de morir formula un ruego semejante (Garci Rodríguez de Montalvo, Amadís de Gaula, II, pág. 1141, nota 49).
} 
aquel para parodiar el asunto, lo que, de nuevo, denota la vigencia y popularidad de nuestro texto ${ }^{25}$. En la tradición oral moderna el romance pervive y se oye en algunas zonas ${ }^{26}$.

No es extraño, por tanto, que una mano de la primera mitad del XVI, al hacer una prueba de escritura, garabatee en el códice hoy custodiado en la Biblioteca Nacional los dos primeros dieciseisílabos de un texto, que, por entonces, debía de sonar con fuerza y por todas partes:

Muerto estava Durandarte caído par de una fuente, al pie duna gran montaña, debaxo una verde rama ${ }^{27}$.

Ahora bien, a diferencia de lo que sucede otras veces con estos apuntes ocasionales, que simplemente nos permiten saber algo más sobre la cronología y difusión de los textos que recogen, en este caso la probatio calami nos ofrece una variante antigua de gran interés pues, no solo nos transmite lo que, presumiblemente, se oía en la tradición oral en la primera mitad del XVI, sino que nos hace llegar una versión del romance de la que, como enseguida veremos, no teníamos noticia.

Los testimonios conocidos hasta ahora de esta pieza, casi todos conservados en fuentes que remontan al siglo XVI, son varios y en ellos encontramos diferencias, algunas bien significativas ${ }^{28}$. Aunque en este punto inicialmente mi

${ }^{25} \mathrm{Y}$ parece que «En el curso de las reelaboraciones sufridas por [...] 'Muerto yaze (queda) Durandarte' (y no en las de 'Oh Belerma, oh Belerma'), nacieron algunos de los detalles que Cervantes explota cómicamente en su relato» («Hallazgo de una poesía marginada», pág. 4). Sobre las parodias de Góngora y Cervantes, véase Gornall y Smith, «Góngora, Cervantes, and the Romancero», Maxime Chevalier, «Cervantes frente a los romances viejos», Voz y Letra, 1, 2, 1990, págs. 191-196, y Julio Alonso Asenjo, «Quijote y romances: usos y funciones», Historia, reescritura y pervivencia del Romancero: Estudios en memoria de Amelia García-Valdecasas, Rafael Beltrán, ed., València, Universitat de València, 2000, págs. 25-61; para un panorama más general, véase Maxime Chevalier, «La fortune du Romancero ancien (fin du XVe S.-Début du XVII')», Bulletin Hispanique, LXXXX, 1-2, 1988, págs. 187-195.

${ }^{26}$ Algunas de esas versiones sobre Durandarte, de Asturias y Andalucía, pueden verse en la Sede del Proyecto sobre el Romancero pan-hispánico (<http://depts.washington.edu/hisprom/> [consultada: 12-06-08]; debe pincharse en la Base de datos de romances).

${ }^{27}$ Regularizo la ortografía ajustándome al uso moderno en el empleo de $i$ con valor vocálico (aparece caýdo) y desarrollo verde, que aparece abreviado.

${ }^{28}$ Así, por ejemplo, en cuanto a la extensión del romance, posiblemente la más larga de las versiones quinientistas sea la incluida en los pliegos del XVI hoy custodiados en la Biblioteca Nacional (véase infra apartado 1.3 del esquema), que contiene 24 dieciseisílabos (la recreación de Juan de Ribera -apartado 1.7- es también notable, pues incorpora 33 versos dieciseisílabos, pero nos lleva a comienzos del XVII). En el extremo opuesto, contamos con la brevedad del romance glosado por López de Villalobos (siete versos dieciseisílabos). Por lo que toca a las citas incluidas en textos ajenos (prescindo aquí de las glosas), lo habitual es que se recoja solo el primer verso, como hace Baltasar de Alcázar, o los dos primeros, como sucede en el disparate de Romero de Cepeda; con todo, puede incorporarse algún verso más, como ocurre con el texto de Argüello (véase infra pág. 291). 
intención era remitir al magnífico estudio de Diego Catalán, que ha examinado con detalle algunas de esas variantes y que, además, ofrece la relación de buena parte de los testimonios, he debido, sin embargo, acercarme al problema para incluir algunos no contemplados por este investigador y para subsanar ciertas imprecisiones $^{29}$. El romance aparece exento en algún caso, pero lo más frecuente es que se vincule a otro texto, ya sea porque haya sido glosado, ya porque se incorpore en ensaladas o porque alguno de sus versos se recoja a modo de cita, ya porque dé lugar a una refacción o recreación posterior; todos estos procesos, en último término, apuntan al enorme éxito del que gozó la composición original $^{30}$. Asimismo, como se notará en el breve esquema que a continuación se ofrece sobre las presencias textuales del romance, «Muerto yaze Durandarte» se copia en pliegos sueltos, el vehículo más común de difusión del romancero, pero también en cancioneros y romanceros, así como en alguna colección poética de un autor individual.

\section{Glosas, ENSALADAS, CITAS, RECREACIONES ${ }^{31}$}

1.1. Glosa de Juan Sánchez Burguillos «Por pago de mis dolores» ${ }^{32}$ (s. XVI)

1.1.1. París, Biblioteca Nacional, ms. Esp. 371, f. 44 (PN 371)

1.1.2. Madrid, Real Biblioteca, ms. II-617, f. 250 (MP 617) (s. XVI)

1.1.3. Madrid, Real Biblioteca, ms. II-2803, f. 108 (MP 2803) (s. XVI)

1.1.4. Madrid, Real Biblioteca, ms. II-1580, f. 68 (MP 1580) (s. XVI)

\footnotetext{
29 Véase «Hallazgo de una poesía marginada», págs. 3-28, especialmente pág. 3, nota 4; pretendo, pues, poner al día el rastreo de Catalán (y, necesariamente, con carácter provisional).

30 Véase al respecto Díaz-Mas, «Algo más sobre romances (y canciones) en ensaladas», págs. 231-232.

31 Periñán y Piacentini, que se ocupan de las glosas quinientistas de romances viejos, no atienden a todas las que aquí se incluyen al contemplar en su estudio tan solo algunas fuentes de las consideradas; sin embargo, sí registran «El más desastrado día» y «De mil ansias rodeado» entre las glosas de «Muerto yaze Durandarte», dos piezas en las que late, en efecto, el eco de esta composición, pero que, a mi jucio, no han de considerarse glosas de nuestro romance (véase infra nota 50).

${ }^{32}$ En la relación de manuscritos sigo la convención habitual en los trabajos sobre colecciones poéticas quinientistas (muy similar a la fórmula aplicada por Dutton en el $C s X V$ ) de denominar abreviadamente las fuentes a partir del lugar en que se localizan y de la biblioteca que los custodia; cierra la sigla la signatura del códice. En el caso de la Real Biblioteca, antes Biblioteca de Palacio, los he identificado acogiéndome a la antigua denominación de la Biblioteca, MP (prescindo en este caso de la referencia de Dutton para alguna de estas fuentes considerada en el Cs $X V$ ).
} 
1.1.5 Madrid, Real Biblioteca, ms. II-531, f. 40 (MP 531) ${ }^{33}$

(h. 1590)

1.1.6. Barcelona, Biblioteca Universitaria, ms. 1649, f. 123 (BU 1649) ${ }^{34}$ (s. XVI)

1.2. Glosa de Francisco López de Villalobos «Aunque nuevas de pesar» Cancionero general de obras nuevas (1554)

1.3. Glosa anónima «Quando el gran Carlos quería» Pliegos sueltos (NDPS 659 y 660) ${ }^{35}$

h. 1550

1.4. Ensalada de Francisco de Argüello «Quitarme podeys la vida» Pliego suelto (NDPS 29)

h. 1550 ?

1.5. Disparate de Joaquín Romero de Cepeda «En medio del verano» ${ }^{36}$ Obras

(1582)

1.6. Cita de Baltasar del Alcázar en «¿Quién os engañó, señor» ${ }^{37}$ Diversas fuentes (ss. XVI y XVII)

1.7. Recreación de Juan de Ribera Pliego suelto (British Library) (1605)

\footnotetext{
${ }^{33}$ La glosa aquí recogida cuenta solo con cinco estrofas, de modo que los versos del romance incorporados son muy pocos.

${ }^{34}$ Catalán omite la referencia a este manuscrito que contiene la glosa de Burguillos, del que, sin embargo, ya daba noticia Alberto Blecua (véase «El Cancionero del Conde de Monteagudo», Homenaje a la memoria de don Antonio Rodríguez-Moñino 1910-1970, Madrid, Castalia, 1975, págs. 93-114, especialmente pág. 99, núm. 62, y, del mismo autor, «Juan Sánchez Burguillos, ruiseñor menesteroso del siglo XVI», Estudios sobre el Siglo de Oro: Homenaje al profesor Francisco Ynduráin, Madrid, Editora Nacional, 1984, págs. 69-103, especialmente pág. 95, núm. XLIII).

${ }^{35}$ Citaré de forma abreviada (NDPS) la magna obra de Antonio Rodríguez-Moñino Diccionario de Pliegos sueltos poéticos (siglo XVI), que manejo a partir de la versión actualizada Nuevo Diccionario de Pliegos sueltos poéticos (siglo XVI), ed. corregida y actualizada por Arthur L.-F. Askins y Víctor Infantes, Madrid, Castalia, 1997.

${ }^{36}$ No da cuenta Catalán de la existencia de este testimonio de Romero de Cepeda, del que ya se informa en Giuliana Piacentini, «Romances en ensaladas y géneros afines», El Crotalón: Anuario de Filología Española, 1, 1984, págs. 1135-1173 (especialmente pág. 1158), y que también se relaciona en José J. Labrador Herraiz, Ralph A. DiFranco, Tabla de los principios de la poesía española. Siglos XVI-XVII, Cleveland, Cleveland State University, 1993.

${ }^{37}$ Nada dice Catalán tampoco de la cita Baltasar de Alcázar, que sí es considerada por José J. Labrador Herraiz, Ralph A. DiFranco y Antonio López Budia en su edición del Cancionero sevillano de Lisboa, Sevilla, Universidad de Sevilla, 2003, págs. 286-287.
} 


\section{CANCIONEROS, ROMANCEROS Y OTRAS COMPILACIONES DE POESÍA}

\subsection{Cancionero de romances 1550}

Integrado en «Oh Belerma, oh Belerma»

2.2. Tercera parte de la Silva de romances 1551

2.3. Cancioneiro de Évora

$$
\text { (s. XVI) }
$$

2.4. Madrid, Real Biblioteca, ms. II-961, f. 101v.-102r. (MP II-961) $)^{38}$ (h. 1580)

2.5. Madrid, Biblioteca Nacional, ms. 1317, f. 443v. (MN 1317)

$$
\text { (s. XVI) }
$$

2.6. Juan Timoneda, Rosa de amores

2.7. Damián López de Tortajada, Floresta de varios romances (1646)

2.8. ¿Impreso perdido?

Como se observa, debemos sendas glosas de «Muerto yaze Durandarte» a dos autores bien conocidos del XVI, Juan Sánchez Burguillos y Francisco López de Villalobos: la de Burguillos, «Por pago de mis dolores», que Catalán supone de gran antigüedad, no aparece siempre explícitamente atribuida al poeta y se localiza en diferentes fuentes manuscritas del XVI, en las que presenta «variantes y deturpaciones varias» ${ }^{39}$; la de Villalobos, «Aunque nuevas de pesar»,

38 Tampoco contempla Catalán este códice, que ofrece, en realidad, una versión distinta de las seis que él establece, posiblemente deturpada (véase infra nota 56).

39 Sobre la consideración de su antigüedad, véase «Hallazgo de una poesía marginada», pág. 3, nota 4; la frase citada en la misma pág. Se halla en seis fuentes manuscritas: MP 617, MP 531, MP 1580, MP 280, PN 371 y BU 1649; aun cuando no consta nombre de autor en otras versiones de la glosa, la de MP 617 la imputa, inequívocamente, a Burguillos, de quien, además, se copian antes y después otras producciones. Piacentini y Periñán ofrecen la edición crítica del texto de Burguillos tan solo a partir de las versiones recogidas en los códices custodiados en la Real Biblioteca; véase Glosas de romances viejos, págs. 184-186, núm. 38.I. Aportan la relación completa de testimonios del texto de Burguillos Ralph A. DiFranco, José J. Labrador Herraiz y C. Ángel Zorita en Cartapacio de Francisco Morán, pág. 472, núm. 210, y editan esta versión, MP 531 (pág. 98, núm. 210), y la contenida en MP 617 (Cancionero de poesías varias: Manuscrito $n^{\circ} 617$ de la la Biblioteca Real de Madrid, Madrid, Visor, 1994, págs. 411-412, núm. 387). Labrador y DiFranco, por su parte, ofrecen también el testimonio de MP 2803 (Cancionero de poesías varias manuscrito 2803 de la Biblioteca de Palacio de Madrid, Madrid, Patrimonio Nacional, 1989, págs. 188-189), miscelánea a la que, en conjunto, también atienden Yolanda Clemente San Román y María Dolores Cigüeña Beccaria («Descripción bibliográfica del Ms. II-2803 de la 
recoge tan solo 14 octosílabos del romance y se halla en el Cancionero general de obras nuevas publicado por Esteban G. Nágera en Zaragoza el año de $1554^{40}$. Además, hay una glosa anónima, «Quando el gran Carlos quería», recogida en pliegos sueltos quinientistas, que, en opinión de Rodríguez-Moñino, «parecen burgaleses de alrededor de 1550 y son iguales» ${ }^{41}$; precediendo a la glosa, figura el romance viejo ${ }^{42}$. Nuestro texto se incorporó, asimismo, en otro pliego, hoy custodiado en la British Library, que contiene obras de Francisco de Argüello y que Rodríguez-Moñino considera «muy antiguo» aun cuando puede asignársele la fecha de $1550^{43}$; en concreto, se insiere en la com-

Biblioteca de Palacio», Revista de Filología Románica, 6, 1989, págs. 231-242). Ofrece la transcripción y el estudio del texto de Durandarte recogido en MP 2803 Catherine Soriano del Castillo, quien, sin embargo, desconoce la autoría de Burguillos, presumiblemente porque el manuscrito no deja constancia del nombre de este poeta; véase «'Durandarte y Belerma' en el manuscrito II-2803 de la Biblioteca de Palacio», Filología Románica, 7, 1990, págs. 197-217 (sobre las hipótesis de esta investigadora a propósito de la autoría, véase pág. 203). El códice de la Biblioteca Universitaria de Barcelona ha sido estudiado por Alberto Blecua en «El Cancionero del Conde de Monteagudo», en donde incluye el listado de las obras recogidas (véanse págs. 96-99); no he podido consultar este manuscrito. Por lo que concierne al códice de París, del que da cuenta Alfred Morel-Fatio en su Catalogue des manuscrits espagnols et des manuscrits portugais, Paris, Imprimerie Nationale, 1892, págs. 225-227 (obra digitalizada y accesible ahora en la dirección http://www.bnf.fr/pages/catalogues.htm [consultada: 12-06-08]), he podido consultar la versión de PN 371 gracias a la amabilidad del profesor José Labrador Herraiz, quien me ha facilitado también el acceso a las páginas correspondientes a la glosa contenidas en Linda Lesack, A Critical Edition of MS Espagnol 371 of the Bibliothèque Nationale (Paris): Spanish Poetry of the Sixteenth Century, Tesis doctoral, University of Missouri-Columbia, 1973 (págs. 285-287).

${ }^{40}$ Véase Cancionero general de obras nuevas (Zaragoza, 1554), Carlos Clavería, ed., Barcelona, Delstre's, 1993, págs. 161-163, y Piacentini y Periñán, Glosas de romances viejos, pág. 192, núm 38.IV. En el Cancionero general de obras nuevas figura, inmediatamente antes, un texto que también recupera otro romance de Durandarte: «Durandarte, Durandarte, / buen cavallero provado» (ibíd., págs. 160-161).

${ }^{41}$ Silva de romances (Zaragoza, 1550-1551), pág. 41. Puede verse la referencia a estos pliegos en NDPS, núms. 659 y 660 . La versión de los pliegos es la más extensa de las quinientistas; publicada ya por Wolf en su Primavera, resulta accesible en la mencionada página web Bases de datos del romancero de Petersen (<http://depts.washington.edu/hisprom/> [consultada: 12-06-08]); se incluye también en Giuseppe Di Stefano, ed., Romancero, Madrid, Taurus, 1993 págs. 207208, donde se ofrece alguna bibliografía. Contamos, por fin, con las clásicas ediciones facsímiles de los pliegos: para NDPS 659, véase Pliegos poéticos españoles de la Universidad de Praga, I, Madrid, Joyas Bibliográficas, 1960, núm. 17; para NDPS 660, Pliegos poéticos góticos de la Biblioteca Nacional de Madrid, II, Madrid, Joyas Bibliográficas, 1957-1961, n. ${ }^{\circ} 86$.

${ }^{42}$ Interesa destacar que, entre la versión del romance viejo que se ofrece en primer lugar y la contenida en la glosa, hay algunas modificaciones, presumiblemente imputables al anónimo glosador. Puede verse tanto el romance exento como el glosado en Piacentini y Periñán, Glosas de romances viejos, págs. $188-191$, n. ${ }^{\circ} 38$. III.

${ }^{43}$ Véase Silva de romances (Zaragoza 1550-1551), pág. 41; también incide en la misma idea al editar la Floresta de varios romances, pág. 28, en donde afirma que es «bastante arcaico». Askins, en el estudio que precede a la edición facsímil de los pliegos, anota la fecha de 1550 entre interrogantes; véase Pliegos poéticos españoles de The British Library, Londres (Siglo XVI), ed. facsímil precedida de una presentación y notas bibliográficas por Arthur Lee-Francis Askins, 
posición que comienza «Quitarme podeys la vida», una ensalada que alternativamente intercala fragmentos de romances y villancicos: «Muerto queda Durandarte» ocupa el quinto lugar y de él se copian tan solo cuatro octosílabos ${ }^{44}$. Algo más tarde volvemos a encontrar versos del romance en la producción de Joaquín Romero de Cepeda, poeta extremeño cuya obra se publica en Sevilla en $1582^{45}$; nuestra pieza se integra en uno de los últimos textos del impreso, «En medio del verano», que es un largo disparate, tal como precisa el título (Nueva guerra en muy graciosos disparates que glosan romances viejos $\left.{ }^{46}\right)$ : de «Muerto yaze Durandarte», como del resto de los romances, se transcriben los dos primeros octosílabos ${ }^{47}$. El primer octosílabo del romance es citado también por el sevillano Baltasar del Álcazar en «¿Quién os engañó, señor», un texto satíricoburlesco en el que el poeta dirige sus dardos contra un caballero impotente, Francisco Chacón: hacia el final de la composición, entrevera entre los suyos «versos citados al pie de la letra o remodelados para ser incluidos sin dislocaciones semánticas» que pertenecen a «varios conocidísimos romances del ciclo épico castellano, sobre los que aplica una pauta paródica que transforma su sentido inicial: don Sancho, el conde Claros o Durandarte se convierten de este modo en evidentes símbolos fálicos» ${ }^{48}$. Finalmente, es preciso hablar de una re-

Madrid, Joyas Bibliográficas, 1989, 4 vols., n. ${ }^{\circ} 3$. Se ofrece la referencia del pliego en NDPS núm. 29 , en donde se informa también de que se ha localizado otro ejemplar.

${ }^{44}$ Cronológicamente es la primera de las ensaladas que incluye Piacentini en su repertorio; véase «Romances en ensaladas», pág. 1137. Esta investigadora pone en relación los versos citados por Argüello con «Oh Belerma, oh Belerma», composición que, como se ha visto, integra «Muerto yaze Durandarte» en la versión del Cancionero de romances de 1550; no obstante, hace notar con acierto: «los dos últimos [versos: 'tan malas lançadas tiene / que le atrauiessan ellalma'] no aparecen en el texto del romance».

${ }^{45}$ De la producción poética de este autor se ha ocupado Antonio Rodríguez-Moñino, Joaquín Romero de Cepeda: poeta extremeño del siglo dieciséis (1577-1590), Badajoz, Centro de Estudios Extremeños, 1941. Puede verse ahora una síntesis de su biografía en Joaquín Romero de Cepeda, Teatro, estudio introd. y notas de Reyes Narciso García-Plata, Cáceres, Universidad de Extremadura, 2000, págs. 9-17. Posiblemente nacido hacia 1540 en Badajoz, compone ya hacia 1566, momento en que puede fecharse alguno de sus poemas (Teatro, pág. 20).

${ }^{46}$ Ha sido editado por Marcel Gauthier [R. Foulché-Delbosch], «De quelques jeux d'esprit», Revue Hispanique, XXXIII, 1915, págs. 385-345, especialmente págs. 419-424.

${ }^{47}$ Véase Romero de Cepeda, Obras, pág. 118v.

${ }^{48}$ Alcázar produce su obra en la segunda mitad del XVI. Puede verse la edición Baltasar del Alcázar, Poesía, Valentín Núñez Rivera, ed., Madrid, Cátedra, 2001, las citas en la pág. 81; sobre su figura y su producción, véanse págs. 11-110 y, para el texto, págs. 430-440 (en el v. 89 se cita tan solo el primer octosílabo: «Muerto yace Durandarte»). Doy las gracias al profesor Labrador por la noticia de este testimonio, del que deja constancia en la edición del Cancionero sevillano de Lisboa, si bien allí se recoge este verso tanto en el apartado dedicado a «Muerto yaze Durandarte» como en el de «Oh Belerma, oh Belerma», ya que, según vimos, la versión del Cancionero de romances de 1550 integra también «Muerto yaze Durandarte»; véase Cancionero sevillano de Lisboa, págs. 286-287. Núñez Rivera piensa, igualmente, que los romances citados en «¿Quién os engañó señor», «a tenor de las variantes que presentan, fueron tomados muy probablemente del Cancionero de romances (Amberes 1550)»; véase su edición, pág. 81. 
fundición tardía, recogida también en un pliego suelto de principios del XVII, debida posiblemente a Juan de Ribera; es esta una versión extensa y muy distinta a las hasta ahora consideradas: en ella se introduce un nuevo personaje, pues Montesinos, sintiéndose incapaz de arrancar el corazón a Durandarte, transmite el encargo a un escudero del muerto que, oportunamente, se allega al lugar ${ }^{49}$.

Todavía se han tenido en cuenta otros textos en los que, ciertamente, aparecen ecos de nuestro romance, pero que, desde mi punto de vista, y pese a las

${ }^{49}$ Este pliego suelto fue considerado por Ramón Menéndez Pidal como «el último pliego [...] de la tradición oral» (véase Romancero Hispánico: Hispano-portugués, americano y sefardí, II, Madrid, Espasa-Calpe, 1953, págs. 193-194; véase también María Cruz García de Enterría, Sociedad y poesía de cordel en el Barroco, Madrid, Taurus, 1973, págs. 375-376). De él no solo da noticia Bartolomé José Gallardo en su Ensayo de una biblioteca española de libros raros y curiosos (Madrid, Gredos, 1968, 4 vols.), sino que allí se transcribe, entre otros, nuestro texto (vol. IV, núm. 3619, págs. 94-99). Sobre el pliego puede encontrarse información en María Cruz García de Enterría, Catálogo de los pliegos poéticos españoles del siglo XVII en el British Museum de Londres, Pisa, Giardini, 1977; en la entrada correspondiente al núm LI se dice sobre el contenido: «Nueue Romances», entre los que se incluye, en cuarto lugar, el de Durandarte y se precisa, además, «Compuestos por Iuan de Ribera. Y con licencia impresos. Año de 1605». Luego, en uno de los apéndices del Catálogo (pág. 248, sig. 011451) se proporciona una sucinta descripción sobre su procedencia y aspecto físico. Más difícil es determinar la intervención de Juan de Ribera, que pudo haber rehecho nuestro romance (esta versión es, desde luego, tan distinta a la tradicional que, en su Ensayo, Gallardo, en vista de las diferencias, antepone a esta la recogida en los pliegos sueltos quinientistas; IV, págs. 95-96). No puede, sin embargo, excluirse que Ribera simplemente se limitase a coleccionar el texto o a componerlo tipográficamente para la imprenta como parece haber hecho en otros casos en el mismo pliego (esto puede suponerse, por ejemplo, del romance «Helo, helo por do viene»). Lo cierto es que ya Agustín Durán, que daba noticia del pliego sin haberlo visto, dudaba de si «Rivera es solo el colector ó reformador, y no el autor de ellos» (véase Agustín Durán, «Catálogo por orden alfabético de varios pliegos sueltos impresos en el siglo XVII», en Romancero general o colección de romances castellanos anteriores al siglo XVIII, I, Madrid, Rivadeneyra, 1849, pág. lxxxiii); y lo mismo hizo Fernando Wolf, quien afirmaba: «No parece ser Ribera el autor, y por lo menos no lo es de todos estos romances» (véase Historia de las literaturas castellana y portuguesa, Segunda parte, traducida del alemán por Miguel de Unamuno con notas y adiciones de Marcelino Menéndez y Pelayo, Madrid, La España Moderna, 1895, pág. 66). Catalán parece inclinarse por imputar la refundición de «Muerto queda Durandarte» a Juan Ribera («Hallazgo de una poesía marginada», pág. 3, nota 4), a quien no duda en considerar mero editor del Infante vengador, contenido en el mismo pliego (véase este romance en <http://cuestadelzarzal.blogia.com> [consultada: 12-06-08]). Es posible que, en efecto, Ribera recogiese (quizás retocándolos levemente) algunos de los romances viejos en su pliego y rehiciese, en cambio, «Muerto queda Durandarte»; en este sentido, importa indicar que Durán ofrece la referencia de otro pliego de Juan de Ribera de 1604: «Romance de un milagro, compuesto por Juan de Rivera» (Romancero general, pág. lxxxiv), que Fernando Wolf localiza en la Biblioteca Imperial de Viena (véase Historia de las literaturas, págs. 81-82). No he podido, sin embargo, identificar este otro pliego de Ribera, que he buscado en vano; agradezco a Nieves Pena Sueiro la ayuda que me prestó en esta fallida búsqueda. Sin que el dato aclare el panorama, es interesante consignar que, algo más tarde, un impresor de este nombre, del que no se conocen datos biográficos, saca a la luz en Sevilla, entre 1657-1659, tres impresiones de distintas obras; véase Juan Delgado Casado, Diccionario de impresores españoles (siglos XV-XVII), II, Madrid, Arco/Libros, 1996, s. v. Ribera, Juan de. No es imposible que se trate del mismo impresor, pero parece bastante improbable que, si estaba activo ya en 1604, continuase trabajando aún en 1657-1659. 
semejanzas, con propiedad no deben tomarse como atestiguaciones de «Muerto yaze Durandarte»; así, entre las glosas quinientistas de esta pieza suelen, por ejemplo, incluirse dos anónimas que comienzan «El más desastrado día» y «De mil ansias rodeado». Aun cuando las composiciones en ellas glosadas guardan relación con la que aquí nos ocupa, ofrecen también notables diferencias: en primer lugar, el personaje de Durandarte, que en nuestra pieza es, como vimos, ya cadáver desde el arranque y da enseguida paso a Montesinos, todavía está vivo en estos otros romances (en alguno de ellos, el patetismo se intensifica porque profiere sus últimas palabras); además, el íncipit lógicamente difiere, pues no podría darse por muerto al que todavía no ha fallecido (lo cual hace imposible «Muerto yaze/queda Durandarte»): en un caso («El más desastrado día») nos lleva a «Malferido Durandarte/ se sale de la batalla», un romance, que Catalán considera «nuevo»; en el otro («De mil ansias rodeado») arranca «Triste estava Durandarte/ al pie de una alta montaña $»^{50}$. Asimismo, Labrador, DiFranco y López Budia añaden, entre los testimonios de «Muerto yaze Durandarte», uno más que localizan en una composición de uno de los últimos y más importantes poetas cancioneriles, Juan Fernández de Heredia, «Por la riza y gran plazer $\aleph^{51}$; se trata, en realidad, de una réplica de don Juan a un poema de

\footnotetext{
${ }^{50}$ Piacentini y Periñán recogen ambas entre las glosas de «Muerto yaze Durandarte»: la núm. 38.II, «El más desastrado día» (pág. 187), y la núm. 38.V «De mil ansias rodeado» (pág. 193), esta última ya incluida por Piacentini en su Ensayo de una bibliografía analítica del romancero antiguo: Los textos (siglos XV y XVI). Fascículo II: Cancioneros y Romanceros, Pisa, Giardini, 1986, pág. 108. La primera, «El más desastrado día», se copia en MP 531 inmediatamente después de la de Burguillos y glosa, en realidad, otra composición, «Malferido Durandarte / se sale de la batalla» (interesa constatar que, en uno de los versos, se dice: «Y aportóle su ventura al pie de una verde haya»); según Catalán hay algún otro testimonio de ella: MP II-1580, que parece ofrecer un íncipit deformado «Malferido sale el hombre / de la primera vatalla», pero, además, este romance, sin glosa y más extenso, se copia, como él advierte, en MP II-961 (véase «Hallazgo de una poesía marginada», pág. 15, nota 32; el texto sin glosa puede leerse en C. Ángel Zorita, Ralph A. DiFranco y José J. Labrador Herraiz, Poesías del Maestro León y de Fray Melchor de la Serna y otros (s. XVI), Cleveland, Cleveland State University, 1991, págs. 189-190); al tiempo, según precisa Giovanni Caravaggi, en el Cancionerillo español de la Biblioteca Trivulziana de Milán, ms. 994, ff. 26v-27r, también aparece glosado (véase «Glosas de romances del siglo XVI», «Nunca fue pena mayor»: Estudios de literatura española en homenaje a Brian Dutton, págs. 137-148, especialmente pág. 137). «De mil ansias rodeado», la segunda de las composiciones incluida por Periñán y Piacentini entre las glosas de «Muerto yaze Durandarte», figura en la Flor de romances y glosas, canciones y villancicos, Juan Soler, Zaragoza, 1578, y nos ofrece como íncipit «Triste estava Durandarte / al pie de una alta montaña». Labrador, DiFranco y López Budia, que consignan esta glosa - pero no la anterior- entre los testimonios de «Muerto yaze Durandarte», precisan con acierto: «Se glosan 8 versos que recuerdan los del romance» (Cancionero sevillano de Lisboa, pág. 286; la cursiva es mía). Lo cierto es que, si tomamos en consideración los ecos del romance «Muerto yaze Durandarte», no solo deberíamos atender a estos textos, sino a otros que también presentan claras similitudes como, por ejemplo, el que comienza «Muerto yaze un caballero» (véase, entre otras versiones, la recogida en Poesías del Maestro León, págs. 163-162 y 287).

${ }^{51}$ Véase Cancionero sevillano de Lisboa, pág. 286. Nacido hacia 1480-1485, podemos vincularlo a la corte valenciana del duque de Calabria; es, al decir de Dutton, uno de los poetas «más
} 
Luis de Milán («Dicho me han, señor don Juan») en la que aquel contrahace el romance «Durandarte, Durandarte» ${ }^{52}$.

Además de servir de materia prima para glosas, citas y ensaladas, cabalmente «Muerto yaze Durandarte» se integró en varias colecciones poéticas quinientistas. Según he indicado, se copia en el Cancionero de romances de 1550 como continuación de «Oh Belerma, oh Belerma» ${ }^{53}$. Se incluye también en la Tercera parte de la Silva de romances (Zaragoza, 1551), en donde lo introduce la rúbrica Romance de Montesinos y aparece junto a otras composiciones referidas a la historia de Durandarte ${ }^{54}$. Todavía durante el siglo XVI se le da cabida en el Cancioneiro de Évora, que ofrece una versión muy similar a la contenida en la Tercera Parte de la Silva; ambas «hermanadas», a su vez, con el romance glosado por Burguillos ${ }^{55}$. Asimismo, figura en un cartapacio con el título de Poesías varias (de hacia 1580) que forma parte de un códice facticio de la Real Biblioteca (MP II-961); la pieza parece deturpada, como si se hubiese dejado de copiar algún verso ${ }^{56}$. En el ms. 1317 de la Biblioteca Nacional de Madrid.

importantes de los últimos de estilo cancioneril» ( $C s X V$, VII, pág. 366) y muere en 1549. Para un acercamiento a su figura y a su obra, véase Estela Pérez Bosch, «Juan Fernández de Heredia, poeta del Cancionero general», Cancioneros en Baena: Actas del II Congreso Internacional "Cancionero de Baena», II, Jesús L. Serrano Reyes, ed., Baena, Ayuntamiento de Baena, págs. 261-286; para la transmisión de su obra poética véase Maria D’Agostino, «Apuntes para una edición crítica de la obra poética de Juan Fernández de Heredia», Convivio: Estudios sobre la poesía de cancionero, Vicenç Beltran y Juan Paredes, eds., Granada, Universidad de Granada, 2006, págs. 319-335.

52 La rúbrica de «Por la riza y gran plazer» nos previene ya: Otras suyas en que le scriue un romance que empieza «Duro en l'arte». Para los textos véase Juan Fernández de Heredia, Obras, Rafael Ferreres, ed., Madrid, Espasa-Calpe, 1975, págs. 188-190; el romance en la pág. 190.

53 Véase supra nota 18.

${ }^{54}$ Véase Silva de romances (Zaragoza 1550-1551), pág. 490. Nuestro romance se halla precedido aquí de «Oh Belerma, oh Belerma», que se presenta bajo el rótulo Romance de Durandarte, y está seguido de «Durandarte, Durandarte/ buen cauallero prouado» con idéntico título (Romance de Durandarte); véase Rodríguez Moñino, La Silva de romances de Barcelona, 1561, págs. 115-148. Garvin, que cree «muy difícil» localizar la fuente empleada para esta pieza en la Tercera parte de la Silva, apunta: «La versión más parecida son los versos que se añaden en el Cancionero de romances de 1550 al romance de Oh Belerma, pero como hemos visto repetidamente Nájera no empleó esa edición. Al menos, que por esos años se encuentren tales versiones quizá indiquen la existencia de esta versión en pliegos»; véase «Scripta manent», pág. 274.

55 Cuando Catalán enumera las seis versiones, se refiere a ese hermanamiento; además, integra la versión del Cancionero de Évora, la Tercera parte de la Silva y la glosada por Burguillos en un único apartado, correspondiente a la versión $a$ (véase «Hallazgo de una poesía marginal», pág. 3, nota 4). La pieza del códice portugués podría haber sido transcrita entre 1553 y 1578 ; véase The Cancioneiro de Évora, Arthur L.-F. Askins, ed., Berkeley-Los Angeles, University of California Press, 1965, págs. 21 y 81 (el texto en la última).

56 Para MP II-961, véase Zorita, DiFranco y Labrador Herraiz, eds., Poesías del Maestro León, págs. 202-203. De Durandarte se pasa en el v. 3 a Montesinos (algo común en muchas de las versiones; véase infra nota 74), pero se incurre en una incongruencia semántica y sintáctica, pues no se explicita el cambio de sujeto y ello entorpece la comprensión: «Muerto iaze Duran- 
(MN 1317) se transcribe una versión bastante extensa y de interés, todavía inédita $^{57}$. Juan Timoneda lo incluirá en la primera de sus Rosas de romances, en la de amores $^{58}$; su texto procede de la versión del romance contenida en los pliegos hoy custodiados en la Biblioteca Nacional de Madrid ${ }^{59}$. Posteriormente, Damián López de Tortajada ofrecerá una versión en su Floresta de varios romances, en donde retoca el texto y lo integra en un corto ciclo de cinco romances sobre la historia del caballero francés ${ }^{60}$; en realidad, Tortajada se nutre, en buena medida, de los materiales del Romancero historiado de Lucas Rodríguez, si bien para «Muerto yaze Durandarte» necesariamente recurre a las viejas versiones, de manera que su serie presenta una interesante mixtura del romancero viejo y el romancero nuevo ${ }^{61}$. Finalmente, en el Ensayo de libros raros de

darte al pie de una gran montaña. / Un canto por cavezera, debajo una verde aya. / Desenlazado el hielmo, y el arnés le desarmava, / y por el lado siniestro el corazón le sacava».

${ }^{57}$ Quizás a ello ayude el mal estado de conservación de los folios que contienen nuestra pieza. Puede verse la descripción del manuscrito en Catálogo de manuscritos poéticos castellanos de los siglos XVI y XVII en la Biblioteca Nacional, I, Pablo Jauralde Pou y Manuel Sánchez Mariana, dirs., Madrid, Ministerio de Cultura-Biblioteca Nacional, 1993, págs. 105-117; se trata de un códice de 489 folios copiados por una o quizás varias manos: nuestro romance se halla, junto a otros romances viejos, en uno de los varios folios muy deteriorados, en este caso (f. 443v) «por la perforación de la tinta sobre el papel».

58 Véase Rosa de romances, por Juan Timoneda (Valencia, 1573); hay edición facsímil [Valencia, Castalia, 1963], si bien el texto está también disponible en la digitalización de la obra Romancero castellano, ó colección de antiguos romances populares de los españoles, III, introducción y notas de G. B. Depping, nueva edición con anotación de Antonio Alcalá Galiano, Leispsique, Brockhaus, 1846, pág. 63 (accesible en la dirección electrónica <http://books.google. es/books?hl=es\&id= TL5GAAAAIAAJ\&dq=timoneda+\%22rosa+de+romances $\% 22 \&$ printsec $=$ frontcover $\&$ source=web\&ots= v4Kqj44MCl\&sig=S0nZmjIm5sTqApdo7xw50OzNBj4\#PPA63,M1> [consultada: 12-06-08]).

59 «Hallazgo de una poesía marginada», pág. 4, nota.

60 Por lo que toca a la complicada vida editorial de la Floresta (véase al respecto el estudio introductorio de Rodríguez Moñino, págs. 9-34), la presencia de «Muerto yaze Durandarte» se da ya desde la primera de las ediciones conocidas, la de Valencia de 1646, y perdurará hasta la de Madrid de 1764; la versión de la Floresta de varios romances se encuentra en la Base de datos de romances de Petersen <http://depts.washington.edu/hisprom/> [consultada: 12-06-08]), pero puede verse también la edición de la obra de Rodríguez-Moñino, págs. 240-241.

${ }^{61}$ Lucas Rodríguez acoge en su Romancero historiado (de hacia 1581 o incluso algo antes) diversos ciclos de romances de nueva factura que versan sobre temas consagrados del romancero viejo y, entre ellos, incluye, cuatro dedicados a Montesinos, Durandarte y Belerma; sin embargo, prescinde en este breve ciclo de la materia presentada en «Muerto yaze Durandarte» (para más detalles véase «Hallazgo de una poesía marginada», págs. 16-18). Algo más tarde López de Tortajada rehace esta serie de Lucas Rodríguez y recupera «parte de los pormenores narrativos y expresivos de los romances viejos»; en concreto, por lo que toca a nuestra pieza, lo que hace es reemplazar el tercer romance del Romancero historiado, que trata sobre el cumplimiento de Montesinos de la última voluntad de Durandarte («Echado está Montesinos / al pie de una verde haya») por «una versión del viejo 'Muerto yaze Durandarte / debaxo una verde haya' y otro de nueva invención en que se cuenta cómo Belerma recibe de Montesinos el corazón de su amado ('En Francia estava Belerma / alegre y regozijada')» (véase un estudio más profundo en «Hallazgo de una poesía marginada», págs. 19-20, de donde tomo las citas). 
Gallardo se da cuenta de un cuaderno impreso, de más de 200 folios, que contiene diversas producciones, entre las que figura «Muerto queda Durandarte»; por el contenido no he conseguido identificar este impreso, quizás perdido ${ }^{62}$. La vida de «Muerto yaze Durandarte» se prolonga, pues, por escrito largo tiempo; hoy en día todavía permanece vivo en la tradición oral moderna ${ }^{63}$.

Y cabría recordar aún otros romances sobre el trágico final del personaje, una veta temática que suscitó un enorme interés y en la que parecen haberse ido abriendo nuevos filones. Así, la agonía de Durandarte se plantea de modo algo distinto en dos de los recogidos en un cancionero del último cuarto del XVI que hoy se custodia en la Biblioteca Vaticana, si bien en ambos, como sucede con «Malferido Durandarte» y con «Triste estava Durandarte», el caballero no está todavía muerto cuando se abre el texto y hace uso de la palabra; me refiero a «A la sonbra de una haya» y a «A pie estaua Durandarte» ${ }^{64}$. Asimismo podría mencionarse un curioso contrafactum de «Oh Belerma, oh Belerma» recogido a fines del XVI en el Cancionero sevillano de Lisboa, «Humana naturaleza, / esposa y hermana amada»: convertida Belerma en la Naturaleza huma-

62 Véase Ensayo de una biblioteca española de libros raros, I, págs. 715-718, núm. 585. En la breve presentación que se hace, se indica «Cuaderno de diferentes obras y romances, y coplas diferentes. (Aquí una estampa en madera obra como de fines del siglo XV, que figura una bata1la). Impresas con licencia». Luego se ofrece un índice alfabético de obras con indicación del folio en el que se copia cada una y con alguna precisión de tipo formal (romance, villancico, pareados...). «Muerto queda Durandarte» estaría en el f. 65 e interesa señalar que, por la secuencia de textos romancísticos en la que se integra, se ajusta al mismo orden que ofrece el pliego suelto de Juan de Ribera (sin olvidar tampoco que el verbo empleado en el arranque es también queda): «Aquel rey de los romanos» (f. 62), «Triste estaba el Padre Santo» (f. 63), «Quien en mal punto se engendra» (f. 64), «Muerto queda Durandarte» (f. 65), «Por los caños de Carmona» (f. 66), «Helo, helo por do viene» (f. 66), «Mal se queja don Tristán» (f. 67) y «Paseábase el buen conde» (68). He cotejado, sin éxito, el Catálogo de los manuscritos que pertenecieron a Don Pascual de Gayangos (redactado por don Pedro Roca, Madrid, Tipografía de la Revista de Archivos Bibliotecas y Museos, 1904) localizando las indicaciones que se ofrecen en los índices sobre romances. Dado que alguno de los íncipits consignados por Gallardo es posterior al siglo XV (se recoge, por ejemplo, «Triste estaba el Padre Santo», que alude a acontecimientos de 1527), quizás haya que pensar, como me sugiere Mariano de la Campa, que se habría utilizado una cubierta antigua bajo la cual se dio cabida a varios pliegos sueltos; es mi propósito volver sobre este asunto.

${ }^{63}$ Véase «Hallazgo de una poesía marginal» y también la Base de datos de romances de Petersen: <http://depts.washington.edu/hisprom/> [consultada: 12-06-08].

${ }^{64}$ Pueden leerse los textos en Cancionero de poesías varias: Ms. «Reginensi Latini» de la Biblioteca Vaticana, recientemente editado por José J. Labrador Herraiz, Ralph A. DiFranco y Carmen Parrilla García (Almería, Editorial Universidad de Almería, 2008, págs. 158-160 y 262-263; núms. 167 y 301 respectivamente); en las notas correspondientes a «A la sonbra de una haya / Durandarte está apeado» se ofrece la referencia de otros testimonios (véase pág. 342), a los que puede añadirse MP II-1580, mencionado por Catalán («Hallazgo de una poesía marginada», pág. 15, nota 32). «A pie estaua Durandarte, / a pie está, que no a cavallo» es, en cambio, un unicum, «conmovedor romance, exclusivo de este manuscrito, del francés despidiéndose de su caballo y llamando a voces a Belerma, instantes antes de su muerte» (Cancionero de poesías varias, pág. 37). A propósito de «Malferido Durandarte» y de «Triste estava Durandarte», véase supra nota 50. 
na, Durandarte en Cristo y Montesinos en San Juan, escuchamos las palabras que Durandarte-Cristo pronuncia antes de su muerte ${ }^{65}$. Y es que, en general, el personaje de Durandarte (y no solo su trágico final) parecen haber atraído la atención del público durante el siglo XVI y aun con posterioridad ${ }^{66}$.

Centrándonos ya en el análisis de los testimonios o, si se prefiere, presencias textuales de «Muerto yaze Durandarte», hay que advertir que, en la mayoría de las versiones viejas, como señala Catalán, el romance comienza diciendo algo muy parecido a lo que ofrecía la prueba de pluma del manuscrito 3338 de la Biblioteca Nacional:

Muerto yaze/queda Durandarte al pie de una alta/gran montaña

El protagonista, que aparece ya muerto, figura en el primer hemistiquio, rasgo no infrecuente en los íncipits del romancero ${ }^{67}$; en este caso, como vimos, se precisa su nombre en el cierre del octosílabo. En cuanto al escenario, también este es elemento importante en el arranque de los romances ${ }^{68}$; «una alta/ gran montaña» es el más frecuente, si bien la glosa de Argüello, que solo incorpora cuatro octosílabos, introduce una ligera variante: «Muerto queda Durandarte / al pie de aquella montaña ${ }^{69}$. Y lo cierto es que, si analizamos atentamente el texto contenido en MN 1317, montaña es una lectura que se justifica internamente: en el decimocuarto dieciseísilabo, puede leerse «aquí quedara su cuerpo en esta áspera montaña», solo admisible teniendo en cuenta la introducción previa en el arranque de «una alta montaña» ${ }^{70}$. Por lo que con-

65 Véase la edición de Labrador, DiFranco y López Budia, págs. 28 y 112-114 (el texto en las últimas págs.). Aun cuando en el apartado de notas los editores lo presentan como «contrahecho a lo divino de 'Oh Belerma, oh Belerma' y 'Muerto yace Durandarte'» (pág. 325), una vez más hay que precisar que Durandarte está todavía vivo y que, por tanto, no ha de tomarse como una contrahechura de nuestro romance.

${ }^{66}$ En la Base de datos de romances de Petersen (http://depts.washington.edu/hisprom/ [consultada: 12-06-08]), en el apartado Búsquedas preliminares (ha de pincharse Protagonistas), se consignan los siguientes en relación con el nombre de Durandarte: Durandarte envía su corazón a Belerma [IGRH 0042], Durandarte. A la sombra de una haya [IGRH 1531], A pie estaba Durandarte [IGRH 1534], Durandarte. El cuerpo bañado en sangre [IGRH 1540], Durandarte. el campo en sosiego [IGRH 0623], Los ojos vueltos dos ríos [IGRH 0784] y Malferido Durandarte [IGRH 1528].

67 Véase Ruth House Webber, «Hacia un análisis morfológico de los primeros versos de los romances», De balada y lírica, 1: 3er coloquio internacional del Romancero, I, Diego Catalán et alii, eds., Madrid, Fundación Ramón Menéndez Pidal-Universidad Complutense, 1994, págs. $307-$ 322 (especialmente págs. 308-310). En la Floresta de varios romances de Tortajada en lugar de Durandarte se transcribe por error Durante.

68 Véase Webber, «Hacia un análisis morfológico», págs. 312-313.

${ }^{69}$ De ella no deja constancia Catalán (la cursiva es mía).

${ }^{70}$ El deíctico de la frase «esta áspera montaña» (la cursiva es siempre mía) se explica porque antes ha aparecido ya la montaña. La lectura «en esta áspera montaña», especialmente en lo que 
cierne al verbo que se aplica al participio muerto, se trata de un verbo predicativo (yazelqueda), frente a lo que sucede en nuestro testimonio, en donde localizamos una mera cópula (estava), con una carga semántica mucho menor y más frecuente en el uso, pero que, en cualquier caso, no altera el cómputo silábico al permitir la sinalefa con la sílaba anterior («Muerto estava»). Con todo, mucho mayor interés que las pequeñas variantes de este verso con relación a nuestra probatio pennae reviste, como enseguida veremos, la coincidencia en la «gran montaña».

«Muerto yaze/queda Durandarte» es, como cabría esperar, el íncipit que para el romance se registra en el poema de Juan Sánchez Burguillos; su glosa, una de las muchas piezas de este tipo que compone el autor, cuenta, como hemos visto, con varios testimonios, todos ellos manuscritos, en los que el texto presenta variantes. Por lo que ahora interesa, ha de destacarse que el segundo verso de nuestro mal trazado garabato («caído par de una fuente, debaxo una verde rama») es muy semejante al recogido por este fecundo poeta, nacido entre 1520 y 1530 , y muerto en $1575^{71}$; el segundo verso de la mayoría de las versiones de «Por cabo de mis dolores» dice:

Tendido cabe una fuente debaxo una verde rama.

La glosa de Burguillos incluida en MP 2803 introduce, no obstante, un significativo cambio: «tendido cabe una fuente, al pie de una verde aya»; y es que aquí figura ya el motivo de la «verde aya», que, como veremos, no estaba en la versión primitiva del romance ${ }^{72}$.

En la Tercera parte de la Silva de romances y en el Cancioneiro de Évora encontramos el romance viejo sin glosa, en una versión semejante a la recogida por el llamado «Ruiseñor menesteroso»; con algunas similitudes, pero también con significativas variantes, se registra en MP II-961 ${ }^{73}$. Ahora bien, si en estas fuentes el íncipit no difiere del ya visto, el segundo verso es, en cambio, algo diferente al comentado:

concierne al vértice del verso, puede hoy reconstruirse tan solo a partir de los restos del trazo de las letras que sobrepasan la línea de escritura (el deterioro del folio es el motivo).

${ }^{71}$ Véase Alberto Blecua, «Juan Sánchez Burguillos».

72 Véase Cancionero de poesías varias: Manuscrito 2803, pág. 188; no puede, sin embargo, olvidarse que la fecha que podemos asignarle al códice nos lleva hasta 1582 (ibíd., págs. xxxxiv): nada extraño habría en que por entonces alguien hubiese introducido este retoque en sustitución de la «verde rama», pues, hacia esa época, el motivo de la «la verde aya» había triunfado plenamente (véase infra pág. 300). Desconozco la lectura del segundo verso ofrecida en BU 1649, pues Blecua recoge tan solo el primer octosílabo; véase «El cancionero del conde de Monteagudo», pág. 99, núm. 123.

${ }^{73}$ Sobre la versión de la Tercera parte de la Silva y del Cancionero de Évora, véase supra notas 54 y 55; para la de MP II-961, supra nota 56 e infra nota 74. 
Un canto por cabecera debaxo una verde aya ${ }^{74}$

Y, yendo todavía un paso más allá, la «verde aya» acaba por alzarse en otras versiones hasta el primer verso, de manera que surge un nuevo íncipit:

$$
\text { Muerto yaze Durandarte debaxo/al pie de una verde aya }{ }^{75}
$$

El motivo de la «verde aya» parece, así, haber alcanzado un gran éxito, de manera que acabó por imponerse «en la imaginación de cuantos trataron el tema a fines del siglo XVI según una estética nueva» ${ }^{76}$; al tiempo, otras transformaciones van introduciéndose en el romance, y a veces son debidas más al influjo de poetas y editores de romances que al peso de la tradición, oral o escrita $^{77}$. Hoy en día, en la tradición oral moderna, se recogen algunas versiones

\footnotetext{
${ }^{74}$ En otras versiones el marco en que se localiza a Durandarte yacente contiene menos detalles y el segundo dieciseisílabo introduce sin más a Montesinos, que es, según se explicó, el auténtico protagonista-agente de nuestro romance; así sucede en el Cancionero de romances de 1550 (v. 2: «llorábalo Montesinos, que a su muerte se hallara»), en la versión de MN 1317 (v. 2: «llorávale Montesinos que a su muerte se fallara»), en la que incluyen los pliegos sueltos (NDPS 659 y 660 , v. 2: «con él está Montesinos, que en la muerte se hallara»), en la glosa de Villalobos (v. 2: «con él queda Montesinos que a su muerte se hallara»), así como en la Rosa de Timoneda (v. 2: «con él está Montesinos, que en la muerte le halla») y en la de Floresta de varios romances (v. 2: «con él está Montesinos que a la su muerte se halla»); la reelaboración de 1605 introduce algún que otro cambio pero también pasa a centrarse en Montesinos (v. 2: «en sus brazos le tenía Montesinos que lloraba»). La glosa de Argüello sigue ocupándose en el segundo verso de Durandarte, pero no para referirse al marco que lo rodea, sino que, apartándose de las demás versiones, se fija en el estado del cadáver (v. 2: «tan malas lançadas tiene que le atraviessan el alma»; véase supra nota 44). La glosa de Burguillos, tras precisar con más detalle el cuadro en que se sitúa Durandarte yacente (v. 2: «tendido cabe una fuente debaxo de una verde rama»), se ocupa de Montesinos en el v. 3: «llorábale Montesinos, que a su muerte se hallara/hallava»), como también se hace en en la Tercera parte de la Silva y en el Cancioneiro de Évora, si bien en estas dos colecciones este es el v. 4, pues antes, como v. 3 , se añade una nueva indicación sobre el marco en que se sitúa el muerto: «todas las aves del monte alrededor le acompañan»; en cambio, en MP II-961, versión del romance también similar en el arranque a la glosada por Burguillos, el texto resulta defectuoso, pues se obvia el nombre de Montesinos, que se menciona mucho después para introducir el parlamento que dirige a Belerma; ello dificulta la comprensión (véase supra nota 56).

${ }^{75}$ Esta versión es la que contiene la glosa anónima en pliegos sueltos (NDPS 659 y 660), la de la Rosa de amores de Timoneda, la de la Floresta de varios romances y la incluida por Romero de Cepeda.

${ }^{76}$ Relaciona Catalán algunos de los romances, que califica de «nuevos», en los que se incorpora el motivo de la verde haya: «Mal ferido Durandarte / se sale de la batalla», «A la umbra de una haya / Durandarte está apeado», «Echado está Montesinos / al pie de una verde haya» y «De una fragosa montaña / en la parte más espesa» (véase «Hallazgo de una poesía marginada», pág. 15, nota 32).

${ }^{77}$ Estudia Catalán, en concreto, el peso de Damián López de Tortajada, que retoca y rehace romances; algunas de esas modificaciones triunfan y se encuentran en la tradición oral moderna. No obstante, ya que nuestra prueba de pluma no nos ha conservado más que los dos primeros dieciseisílabos, remito, para otros detalles también de interés en la vida del romance, a su trabajo ya citado.
} 
en las que aparece también esa «verde aya», que, sin embargo, como perspicazmente intuía Catalán,

no podía, claro está, figurar en el discurso del caballero moribundo que constituye el romance de «Oh Belerma, o Belerma»; pero tampoco se encontraba, según creo, en la redacción primitiva del romance narrativo que describe el cumplimiento de la manda ${ }^{78}$.

Lo cierto es que la «gran montaña» y la «verde rama» del apunte del manuscrito 3338 de la Biblioteca Nacional nos acercan a esa redacción primitiva, pues, presumiblemente, nuestro «pendolista» ensayaba su pluma con un texto que venía a su mente porque le resultaba familiar: recordaba lo que había escuchado $^{79}$. Y es que, como bien advierte Armistead a propósito de otra anotación romancística, «semejantes pruebas de pluma no suelen realizarse mediante la copia de un texto escrito, sino más bien con las primeras palabras que saltan a la memoria del amanuense ${ }^{80}$. Los dos dieciseisílabos de «Muerto yaze Durandarte» que figuran en el manuscrito de la Biblioteca Nacional confirman, así, que en la versión inicial, como sospechaba Catalán, no existía la «verde aya» y ofrecen, además, un segundo verso que aporta también variantes con respecto a los demás testimonios que se nos han conservado.

El examen de una humilde prueba de pluma, localizada en el último folio de un códice de la primera mitad del siglo XVI, nos ha proporcionado una nueva y fragmentaria versión de «Muerto yaze Durandarte» hasta hoy desconocida y, al tiempo, nos ha permitido constatar el indiscutible interés de este tipo de intervenciones ocasionales en los códices e impresos.

78 «Hallazgo de una poesía marginada», pág. 14.

79 Aplico el término del que se valen Infantes y Conde (véase «La letra sobre la letra», pág. 683), por más que la mano que copia los versos de «Muerto yaze Durandarte» en el códice 3338 no se esmera en la tarea.

${ }^{80}$ Véase Armistead, «¿Existió un romancero de tradición oral?», pág. 226. 